International Journal of Advanced Chemistry, 9(1)(2021) 25-28
International Journal of Advanced Chemistry
SPC
Website: www.sciencepubco.com/index.php/IJET
Research paper

\title{
The effect of Triton X surfactants on Pb (II) transport rate using bulk liquid membrane systems
}

\author{
Mersiha Suljkanović $^{1}$ *, Jasmin Suljagić ${ }^{2}$, Mustafa Pašić ${ }^{1}$ \\ ${ }^{1}$ Faculty of Natural Sciences and Mathematics, University of Tuzla, Urfeta Vejzagića 4, Tuzla Bosnia and Herzegovina \\ ${ }^{2}$ Faculty of Technology, University of Tuzla, Urfeta Vejzagića 8, Tuzla Bosnia and Herzegovina \\ *Corresponding author E-mail: mersiha.suljkanovic@untz.ba
}

\begin{abstract}
Implementation of the "bulk liquid membrane" (BLM) system was investigated in terms of its efficiency for selective removal of heavy metal ions from natural resources and industrial wastewater. In this paper, the removal of lead (II) ions through a liquid membrane system and factors that influence the process were examined. The research was performed using the homemade transport cell. Two organic solvents were used as liquid membranes: 1,2-dichloroethane and chloroform. Metal ion concentration in aqueous phases was monitored by flame atomic absorption spectrophotometry, after 4 hours of experiment. Macrocyclic ether (dicyclohexano-18-crown-6) was used as ligand for $\mathrm{Pb}$ (II) ions. The effects of nonionic surfactants (Triton X-100, Triton X-45 and Triton X-405) added in the receiving phase of BLM system were investigated. The results showed significant increase in transport rate compared to systems without surfactants. Considering the surfactant structure, transport rate of $\mathrm{Pb}$ (II) ions followed the order: TX-100 > TX-45>TX-405. Presence of TX-100 increased transport of $\mathrm{Pb}$ (II) ions up to $78 \%$ through chloroform and 58\% through 1,2-dichloroethane.
\end{abstract}

Keywords: Bulk Liquid Membrane Transport; Pb (II); Triton X Surfactants.

\section{Introduction}

Possibility for removal of heavy metal ions was investigated by many scientists, considering the high toxicity of these ions for living organisms and their tendency to accumulate in the body. Therefore, finding the most efficient and reliable procedures for their removal has been the final goal among many researchers recently. Bulk liquid membrane (BLM) transport technique have numerous advantages among other membrane techniques, such as: low start-up and operating costs, low carrier, solvent and energy consumption, the easy capability of commercialization and high selectivity (Alguacil et al. 2002). Also, the liquid membrane is considered as a green technology due to its green characteristics, such as being eco-friendly and its low consumption of organic solvent (Chang et al. 2010). The simplicity of this transport technique is reflected in simultaneous processes of: extraction, diffusion and re-extraction of analyte and therefore attracts great attention among researchers (Shokrollahi et al. 2009). Overall transport process occurs in homemade transport cell. The transport cell is simply constructed and contains two aqueous phases (the source phase, SP which contains metal ions that need to be transported and the receiving phase, RP in which the ions will be transported). Between the aqueous phases lies the organic or membrane phase, MP (suitable solvent). In overall transport process, the first step is to extract metal ions from the SP to the MP. Therefore, the membrane phase contains suitable ligand dissolved in it. Metal ions are transferred during transport based on their diffusion through the system, but for the efficient transport, the re-extraction step is required and metal ions should be released from the MP to the RP. The receiving phase is required to contain suitable stripping agent for successful re-extraction step. For designing the procedure which will result in high transport rate, balance between metal-ligand complexation (in the extraction step) and decomplexation (in the re-extraction step) is crucial to achieve. Among the most suitable ligands for many metal ions, polyether ligands are widely used as highly efficient for complexation purposes, due to the presence of oxygen atoms as electron donors in their structures. The level of metal-ligand interactions and the stability of the formed complexes depend on a numerous experimental parameters (Salman et al. 1996). The type of membrane solvent, the type of counterion, the presence of coexisting species and the type of stripping agents are considered the most important parameters. The appropriate values of the stability constants of formed complexes, adequate solubility within the membrane, as well as lipophilicity are required to prevent the ligand from leaking out of the membrane into the solution of the analyte itself. The nature of the membrane solvent is also one of the most important factor in establishing transport efficiency. Researchers (Izatt et al. 1991) highlight the necessity of having valid information for different solvent systems to understand their influence on thermodynamics and complexation kinetics. Some significant solvent parameters are given for dichloromethane (DCM), 1,2-dichloroethane (1,2-DCE), nitrobenzene (NB) and chloroform (CH) in Table 1 (Kakhki et al. 2011). 
Table 1: Solvent Parameters

\begin{tabular}{|c|c|c|c|c|}
\hline Solvent & Dielectric constant, $\varepsilon_{\mathrm{r}}$ & Dipole moment, $\mu(\mathrm{D})$ & Viscosity, $\eta(\mathrm{mPa} . \mathrm{s})$ & Density, $\rho\left(\mathrm{g} / \mathrm{cm}^{3}\right)$ \\
\hline DCM & 8.93 & 1.6 & 0.41 & 1.33 \\
\hline 1,2- DCE & 10.66 & 1.8 & 0.84 & 1.25 \\
\hline NB & 34,82 & 4.02 & 2.03 & 1.19 \\
\hline $\mathrm{CH}$ & 4,81 & 1.15 & 0.56 & 1.49 \\
\hline
\end{tabular}

Authors (Kazemi et al. 2010) proposed a possible mechanism for metal ion transport assuming that the most influential process during transport experiments was the metal ions release from the complex in the membrane phase to the receiving aqueous phase through the contact surface between the two phases.

Considering the crucial importance of the re-extraction step in overall transport mechanism, effect of the receiving phase composition need to be investigated. In this paper, "model transport systems" with known concentrations of $\mathrm{Pb}$ (II) ions and macrocyclic ligand dicyclohexano-18-crown-6) were examined with counter ions (picrates) present, in chloroform and 1,2-dichloroethane as organic solvents. The effect of added nonionic surfactans in RP is presented as metal ion transport efficiency, expressed through the metal ion concentration in aqueous phases of the system, and measured with atomic absorption spectrometric (AAS) technique.

\section{Materials and methods}

\subsection{Preparation of the bulk liquid membrane solutions}

For every transport experiment, two aqueous solutions and one non-aqueous organic solution (liquid membrane), were prepared using following material.

a) Source Phase preparation:

Formic acid buffer solution $(\mathrm{pH}=3$ ), prepared from $\mathrm{HCOOH}$ (purris. p.a., Fluka) and $\mathrm{NaOH}$ (g.r. Merck) used as a medium for SP, in which metal ions and counter ions were dissolved using:

- Standard lead (II) solution $\left.(1000 \mathrm{mg} / \mathrm{L}),\left(\mathrm{Pb}\left(\mathrm{NO}_{3}\right)_{2} \text { in } 0,5 \mathrm{M} \mathrm{HNO}\right)_{3}\right)$ Merck,

- $\mathrm{C}_{6} \mathrm{H}_{3} \mathrm{~N}_{3} \mathrm{O}_{7}$, picric acid (99\%, Kemika).

b) Membrane Phase preparation

Organic solvents: chloroform, $\mathrm{CHCl}_{3}$ and 1,2-dichloroethane, $\mathrm{C}_{2} \mathrm{H}_{5} \mathrm{Cl}_{2}$, (p.a. Kemika) were used as membrane hydrophobic medium for macrocyclic ligand: dicyclohexano-18-crown-6, DCH18C6 (99\%, ACROS ORGANICS).

c) Receiving Phase preparation:

Acetic buffer solution $\left(\mathrm{pH}=5\right.$ ), prepared from $\mathrm{CH}_{3} \mathrm{COOH}$ (purris. p.a., Fluka) and $\mathrm{NaOH}$ (g.r. Merck) was used as a medium for $\mathrm{RP}$, which contained stripping agents and tested nonionic surfactants:

- $\mathrm{C}_{10} \mathrm{H}_{14} \mathrm{~N}_{2} \mathrm{Na}_{2} \mathrm{O} 8$, EDTA disodium salt (p.a. Sigma-Aldrich) as stripping agent,

- Nonionic surfactants: $\mathrm{C}_{14} \mathrm{H}_{22} \mathrm{O}\left(\mathrm{C}_{2} \mathrm{H}_{4} \mathrm{O}\right)_{9,5}$ (Triton X-100), $\mathrm{C}_{14} \mathrm{H}_{22} \mathrm{O}\left(\mathrm{C}_{2} \mathrm{H}_{4} \mathrm{O}\right)_{4,5}$ (Triton X-45) and $\mathrm{C}_{14} \mathrm{H}_{22} \mathrm{O}\left(\mathrm{C}_{2} \mathrm{H}_{4} \mathrm{O}\right)_{40}(\mathrm{TX}-405)$; all from Sigma-Aldrich.

Series of lead (II) working solutions for the calibration curve, were prepared also in appropriate buffer medium and used for calibration purposes.

\subsection{Transport procedure}

Cylindric glass container, i.e. "transport cell", with inner diameter of $5 \mathrm{~cm}$ and central glass tube ( $2 \mathrm{~cm}$ in diameter), have been used for this study (Fahmideh-Rad et al. 2010):

(A)

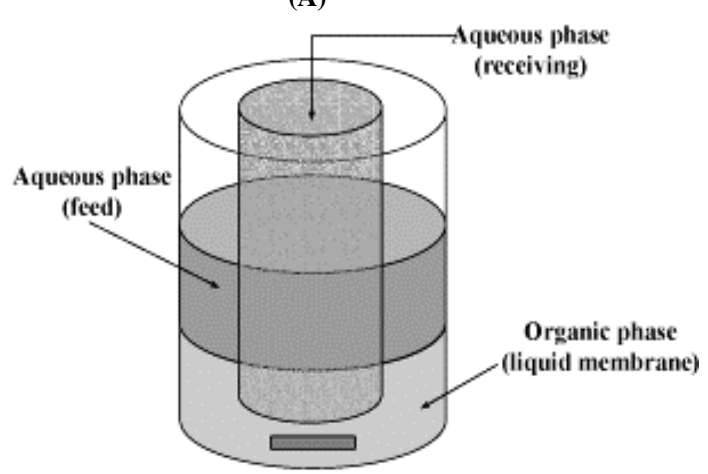

(B)

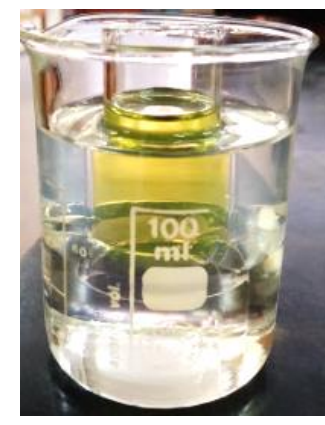

Fig. 1: A) Scheme of A Cylindrical Glass Vessel, "Transport Cell"; B) Homemade Transport Cell Used in Experiments.

Central tube provides physical separation of two aqueous phases: source phase SP, and receiving phase, RP. Membrane phase, MP lies under the aqueous phases and connects them. Constant stirring with a magnetic stirrer is essential to provide that contact surfaces: RP/MP/SP remains flat and well defined (Nipamanjari et al. 2010).

The source phase $(\mathrm{pH}=3)$ contained $10 \mathrm{~mL}$ of a mixture of tested metal ions, $\mathrm{Pb}(\mathrm{II})\left(1 \cdot 10^{-3} \mathrm{~mol} / \mathrm{L}\right)$ and the counter ions, picrates $\left(1 \cdot 10^{-3} \mathrm{~mol} / \mathrm{L}\right)$. The receiving phase $(\mathrm{pH}=5)$, which is outside the central tube, contained $11 \mathrm{~mL}$ of a mixture of stripping agent $($ EDTA, $1 \cdot 10^{-3} \mathrm{~mol} / \mathrm{L}$ ) and nonionic surfactant (TX-100: $7 \cdot 10^{-4} \mathrm{~mol} / \mathrm{L}$; TX-405: $4 \cdot 10^{-3} \mathrm{~mol} / \mathrm{L}$, TX-45: $5.8 \cdot 10^{-5} \mathrm{~mol} / \mathrm{L}$ ). The membrane phase $(\mathrm{pH}=5)$ contained $50 \mathrm{~mL}$ of a suitable ligand $\left(1 \cdot 10^{-3} \mathrm{~mol} / \mathrm{L}\right)$ dissolved in an organic solvent (chloroform or 1,2-dichloroethane).

Both aqueous phases were analysed by atomic absorption spectrometry after 4 hours of mixing and the efficiency of used transport system was determined. 


\subsection{Instruments}

$\mathrm{pH}$ measurements of aqueous solutions were performed using the $\mathrm{pH}$ meter (GLP31 Crison Instruments). Quantification of metal ions removed during the transport experiments was obtained by Flame Atomic Absorption Spectrometry technique, using the instrument Perkin Elmer AAnalyst 200.

\section{Results}

In this paper, the influence of nonionic surfactants added in the receiving phase of the BLM system, were investigated. Investigation was based on the expectation for the interactions between metal ions and nonionic surfactants to occur at the MP/RP interface, enhancing the release of cations into the RP and increasing the removal rate. Transport experiments included nonionic surfactants (TX-100, TX-45 and TX-405) added in the receiving phase with EDTA as stripping agent. Extraction of $\mathrm{Pb}(\mathrm{II})$ ions from the SP was carried out through the complexation of cations with macrocyclic ligand (DCH18C6) within liquid membranes (chloroform and 1,2-dichloroethane). Results were presented in Table 2. from both aspects: removal rate from the SP (extraction efficiency) and transport rate to the RP (reextraction efficiency).

Table 2: Measured Content of $\mathrm{Pb}(\mathrm{II})$ Ions in Aqueous Phases (SP and RP) After 4 Hours of Transport, Using DCH18C6 (10 ${ }^{-3}$ mol/L) as Membrane Ligand and EDTA $\left(10^{-3} \mathrm{~mol} / \mathrm{L}\right)$ as Stripping Agent with Addition of Surfactants

\begin{tabular}{lllll}
\hline Surfactant added in the RP & MP solvent & $\mathrm{Pb}(\mathrm{II})$ remained in the SP $(\%)$ & $\mathrm{Pb}(\mathrm{II})$ removal from the SP $(\%)$ & Transport to the RP $(\%)$ \\
\hline TX-405 & & 20.5 & 79.5 & 87 \\
TX-45 & Chloroform & 13 & 78 & 74.3 \\
TX-100 & 22 & 100 & 78 \\
TX-405 & 0 & 100 & 54 \\
TX-45 & 1,2-dichloroethane & 0 & 100 & 44 \\
TX-100 & 0 & & 58
\end{tabular}

\section{Discussion}

Earlier investigations of the effects of nonionic surfactants dissolved in the membrane phase of BLM systems for Cd(II) transport (Suljkanović et al. 2020) resulted in reduced ammount of cations transported to the RP and similar results were obtained in investigation of BLM transport for $\mathrm{Pb}$ (II) ions, with addition of the same nonionic surfactants in the membrane phase (Suljkanović et al. 2017). Decreased transport rates in these experiments probably resulted from additional interactions between metal ions and surfactants within the membrane phase, which limited their release into the receiving phase. Investigating the influence of the stearic acid, palmitic acid and oleic acid as surfactants in the membrane phase on the cation $\mathrm{Pb}$ (II) transport, authors (Rounaghi et al. 2009) also assumed that the formation of micelles of the fatty acids in the membrane phase trap the crown-cation complex and, therefore, the transport rate of $\mathrm{Pb}$ (II) ion decreases in the presence of stearic, palmitic and oleic acids.

\subsection{Influence of non-ionic surfactants in the RP}

Althought the addition of nonionic surfactants in the MP decreased the transport rates, it has been found that the addition of surfactants (anionic type) in the receiving phase of BLM systems resulted in increased transport rate (Bjelic et al. 2020), due to the interactions between cations and anionic surfactants, which enhanced reextraction step (cation release) into the RP.

Obtained extraction efficiencies in this paper (Table 2) were high as expected (up to 100\% for 1,2-dichloroethane systems), resulted from successful removal of $\mathrm{Pb}(\mathrm{II})$ ions from the SP with suitable ligand DCH18C6 in the membrane phase. Influence of surfactants in the RP is reflected through higher transport rates, compared to earlier investigations of $\mathrm{Pb}(\mathrm{II})$ transport with DCH18C6 (Suljkanović et al. 2017) where transport rates of $55.2 \%$ through chloroform and $28.6 \%$ through 1,2-dichloroethane were achieved.

\subsection{Influence of membrane solvent type}

It is obvious that chloroform membrane enable higher transport rate to the RP, for all used surfactants, compared to 1,2-dichloroethane. Lower viscosity of chloroform (0.56) and also lower dielectric constant value (4.81) compared to 1,2-DCE ( 0.84 and 10.66 , respectively) contributed to higher transport rate obtained by using chloroform as membrane solvent. This is in accordance with earlier investigations (Zadeh Kakhki et al. 2011) where chloroform was proved to be appropriate membrane solvent. Previous research (Suljkanović et al. 2017) showed also higher transport rate for Pb(II) ions using DCH18C6 in chloroform membrane (55.2\%) compared to 1,2-DCE (28.6\%). This solvent was prefferable also in Cd(II) transport experiments with DCH18C6: $30.2 \%$ was transported through $\mathrm{CH}$, compared to $20.5 \%$ through 1,2-DCE (Suljkanović et al. 2017).

\section{Conclusion}

The addition of nonionic surfactants Triton X-100, Triton X-45 and Triton X-405 in the receiving phase which already contained stripping agent, increases transport efficiency due to interactions of $\mathrm{Pb}(\mathrm{II})$ ions with the formed micellar structures in the receiving phase, which enhance decomplexation and metal ions release from membrane to the receiving phase.

Significant interactions between $\mathrm{Pb}$ (II) ions and nonionic surfactants at the MP/RP interface resulted in higher transport rates of $\mathrm{Pb}$ (II) ions (up to $78 \%$ through chloroform and 58\% through 1,2-dichloroethane) compared to transport systems without nonionic surfactants in the receiving phase. Considering the surfactant structure, transport rate of $\mathrm{Pb}(\mathrm{II})$ ions followed the order: TX-100 > TX-45>TX-405. 


\section{References}

[1] Alguacil FJ (2002) Facilitated transport separation of manganese cobalt by a supported liquid membrane using DP-8R as a mobile carrier. Hydrometallurgy 65(1), 9-14. https://doi.org/10.1016/S0304-386X(02)00059-2.

[2] Amini MK, Shamsipur M (1992) Complex formation of hydronium ion with several crown ethers in 1, 2-dichloroethane, acetonitrile, and nitrobenzene solutions. Journal of Solution Chemistry 21, 275-288. https://doi.org/10.1007/BF00647023.

[3] Bjelić E, Suljkanović M, Suljagić J, Kovačević A (2020) Application of Different Ligands to Optimize Cd (II) Removal Through Liquid Membranes. Advances in Analytical Chemistry 10(1), 7-10. https://doi.org/10.14445/23939133/IJAC-V7I1P102.

[4] Bjelić E, Suljkanović M, Suljagić J, Kovačević A (2020) The Role of Sodium Dodecyl Benzen Sulfonate in Removal of Pb (II) ions Through Bulk Liquid Membrane Systems. Proceedings of the IX International conference of social and technological development, 372-377.

[5] Chang SH, Teng TT, Ismail N (2010) Extraction of Cu (II) from aqueous solutions by vegetable oil-based organic solvents. Journal of Hazardous Materials 181, 868-872. https://doi.org/10.1016/j.jhazmat.2010.05.093.

[6] Fahmideh-Rad E, Rounaghi GH, Arbab Zavar, MH, Chamsaz M (2010) Spectrometric determination of Pb ${ }^{2+}$ cation after selective bulk liquid membrane transport using benzo-18-crown-6 as carrier. Der Pharma Chemica 2(6), 8-18.

[7] Izatt RM, Pawlak K, Bradshaw (1991) Thermodynamic and kinetic data for macrocyclic interactions with cations and anions. Journal of Scientific Chemical Reviews 91 (8), 1721. https://doi.org/10.1021/cr00008a003.

[8] Kakhki RMZ, Rounaghi GH (2011) Competitive bulk liquid membrane transport of heavy metal ions. Journal of Chemical \& Engineering Data 56, 3169-3174. https://doi.org/10.1021/je200220d.

[9] Kashanian S, Shamsipur M (1989) Complex formation of alkaline earth cations with benzo-15-crown-5 and some 18-crowns in methanol, dimethylformamide and dimethyl sulfoxide solutions. Inorganica Chimica Acta 155, 203-206. https://doi.org/10.1016/S0020-1693(00)90410-9.

[10] Kazemi MS, Rounaghi GH (2010) Highly selective transport of lead cation through bulk liquid membrane by macrocyclic ligand of decyl-18-crown6 as carrier. Russian Journal of Inorganic Chemistry 55 (12), 1987-1991. https://doi.org/10.1134/S0036023610120272.

[11] Nipamanjari D, Sanjib B, Mukherjee AK (2010) Charge transfer complex formation between TX-100/CCl4. Molecular Physics 108 (11), 15051511. https://doi.org/10.1080/00268971003762126.

[12] Reusch CF, Cussler EL (1973) Selective membrane transport. AlChE Journal 19(4), 736-741. https://doi.org/10.1002/aic.690190409.

[13] Rounaghi GH, Arbab-Zavar MH, Fahmideh-Rad E (2009) Transport Study of Metal Cations Through a Bulk LiquidMembrane Using Benzo-18crown-6 as an Ionophore. Asian Journal of Chemistry 21(2), 1389.

[14] Salman SR, Derwish GAW, Al-Marsoumi SMH, (1996) Molecular complexes of crown ethers, part 4 Complexes of crown ethers with picric acid, Journal of Inclusion Phenomena and Molecular Recognition in Chemistry 25, 295-302. https://doi.org/10.1007/BF01044999.

[15] Shokrollahi A, Ghaedi M, Shamsipur M (2009) Highly selective transport of mercury (II) ion through a bulk liquid membrane. Quimica Nova 32(1), 153-157. https://doi.org/10.1590/S0100-40422009000100029.

[16] Suljkanović M, Nurković E, Suljagić J, (2017) Influence of nonionic surfactants as competitive carriers in Bulk Liquid Membrane transport of metal cations using macrocyclic ligands. Journal of Chemical, Biological and Physical Sciences 8(1), 77-89. https://doi.org/10.24214/jcbps.A.8.1.07789.

[17] Suljkanović M, Bjelić E, Suljagić J, Kovačević A (2020) The Effect Of Nonionic Surfactants on Cadmium (II) Removal Rate Using Bulk Liquid Membrane System. Proceedings of the XI International Scientific Agricultural Symposium "Agrosym 2020”, 645-650. 